\title{
System and Context - On a Discernable Source of Emergent Game Play and the Process-Oriented Method
}

\author{
Barbara Grüter, Miriam Oks, and Andreas Lochwitz \\ Hochschule Bremen, University of Applied Sciences, \\ Flughafenallee 10, 28199 Bremen, Germany \\ \{barbara.grueter, miriam.oks, andreas. lochwitz\} @hs-bremen. de
}

\begin{abstract}
Mobile games are based on the physical movement of players in a game world, combining real world with virtual dimensions. As the real world defies control, the magic circle, the border of the game world, becomes permeable for influences of everyday life. Neither the players nor the designers nor the researchers are able to foresee and fully control the consequences of players' actions in this world. In our paper we introduce a case study. Within this empirical study the difference between the game as a system on the one hand and the context of play on the other hand becomes discernable as a source of emergent game play. We then elaborate on its meaning for the process-oriented method.
\end{abstract}

Keywords: mobile games, system, context, process-oriented method, emergent game play, quantitative method, qualitative method.

\section{Introduction}

Mobile games are based on the physical movement of players within a game world that merges real world with virtual dimensions. This kind of games has been spread meanwhile worldwide embodied by numerous prototypes and accompanied by various debates on the nature of these games: location-based, context-aware, ubiquitous, augmented reality and pervasive [1]. Since 2007 mobile games are becoming commercially relevant, see for example GPS Mission, fastfoot challenge, Parallel Kingdom or locative social media like foursquare and Gowalla. Accordingly the issue of evaluating mobile applications has been put forward [2]. However, evaluating mobile applications researchers face unprecedented theoretical, methodological and organizational issues. Mobile games are situated in the everyday world. As the real world is only partly foreseeable and controllable, players, designers, and researchers of mobile games encounter manifold aspects of everyday life they have to deal with playing, designing and evaluating the game. Similar to Juul [3] we assume each single object, action, and player of game play to be defined by the game system and the context of play (p. 514). We see this difference between system and context as the source of emergent game play, which have to be taken into account methodologically when it comes to study play experiences and to evaluate a mobile game. Today researchers deploy traditional 
HCI methods and seek to adapt them to the novel situation [4]. Ethnographers around Crabtree and the Mixed Reality Lab Nottingham conceive game play as the result of players' actions and consequently look for the particular methods players employ to organize their play action within their own context [5], [6]. Reid et al. propose an emergence-driven research methodology by combining field trials and experiments to discover emergent facets of game play [7]. In this paper we contribute to these studies by zooming in an actual game play process. We want to make the difference between the game system and the context of play empirically discernable as a source of emergent game play and to elaborate on its methodical meaning for the process-oriented method we use for evaluating mobile games.

\section{A Case Study}

In 2006 and 2007 we several times play-tested the mobile game On the Streets we have had developed as a prototype from 2004 to 2007 Meanwhile up to 500 players played the game. In the following we introduce and compare two different, very brief mobile fight events [8], which happened during two small play-tests, one with Chinese players and one with German players. It might be important to note that the goal of our comparison is not to study and explain the cultural difference, but to demonstrate the difference between the game system and the context of play as a source of emergent game play.

\subsection{The Mobile Game On the Streets}

The mobile game On the Streets is played in an urban area divided into squares, we call fields. Players are organized in gangs. A gang consists of one to five runners and a boss who is physically sitting at a Personal Computer in an office and virtually located in the home base of the gang. The goal of the game for each gang is to gain power and influence by capturing as much territory as possible that means fields, and particularly the home base of the other gangs. All runners have a map of the game territory displayed on their PDA's, where they can retrieve detailed information about the field they are currently in as well as about the eight surrounding fields and by which they take action like attacking the opponent.

\subsection{The Play Test - Settings and Observations}

In the late summer 2007 we organized two particular play tests: one with six Chinese players and one with six German players. With regard to our question here, we found that the cultural difference becomes discernable as a difference between the game system, identical for all players, and the context of play, culturally different for the players. Both games have been played with two gangs, each with two runners and one boss, in the urban area around our university. The playground consisted of 16 fields, each of them 30 by 30 meters. 


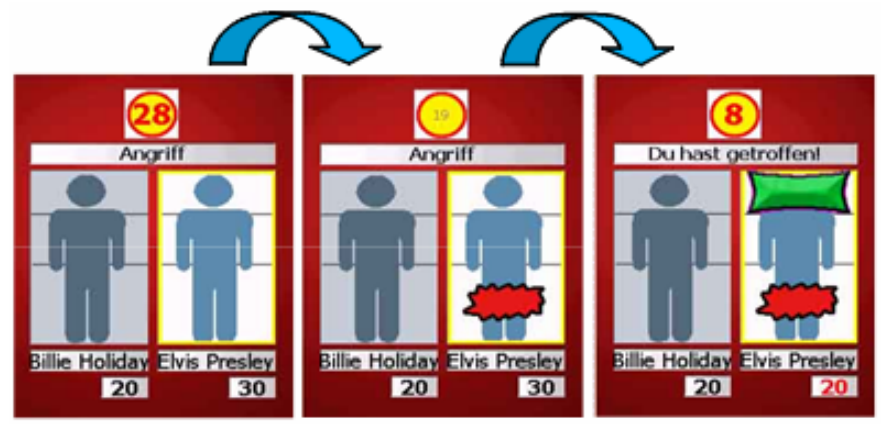

Fig. 1. Fight Mechanics - sequence of fight screens on PDA

The fight mechanics, a component of the game logic, and of the underlying technology, has been used from both player groups. To conquer a field a player has to move into that field. As soon as an opponent player is within the same field each player has the possibility to decide whether he wants to attack or to flee. To attack the opponent they have to identify their enemy physically and to choose the appropriate virtual symbol of their enemy to start the fight.

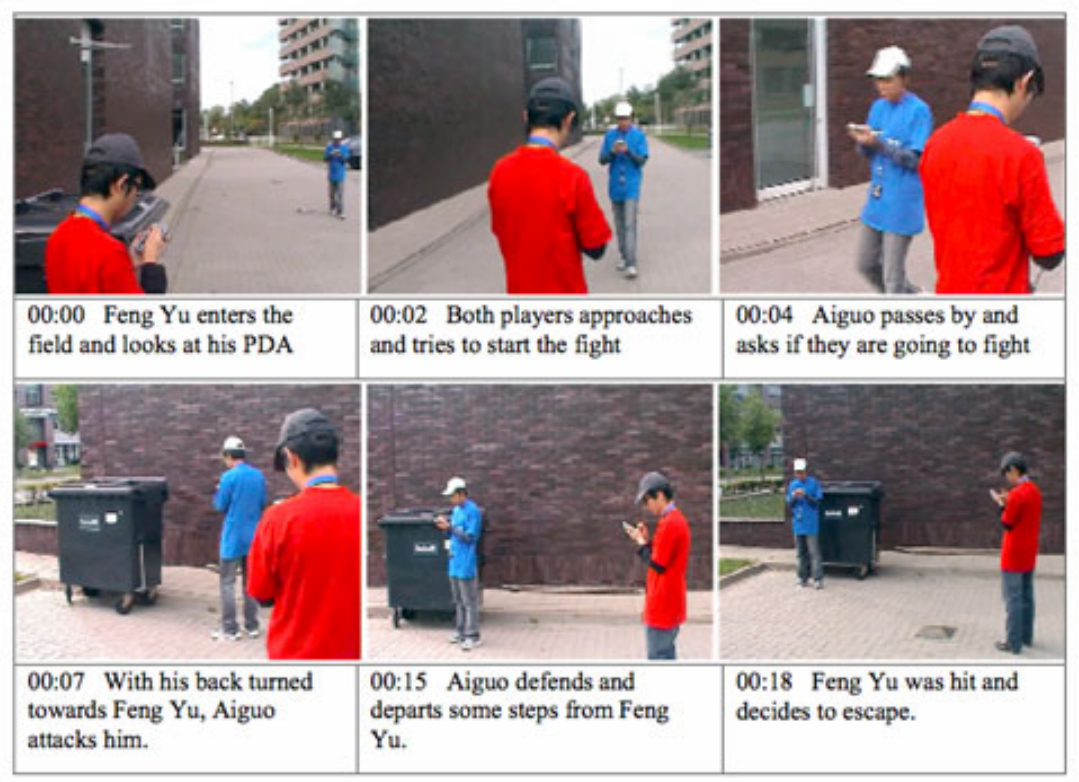

Fig. 2. The Chinese fight

The fight action enabled by the fight mechanics takes place virtually only. Each fight consists of a sequence of rounds, which a player quits by fleeing. The game logic the players deployed was identical. 
However, the players of both groups fought quite differently. The Chinese players fought in a charily manner, kept physical distance to each other and focused on the virtual level. The German players fought in an offensive, expressive manner. They pestered each other, and focused on both, the virtual and the real level, compare Table 1.

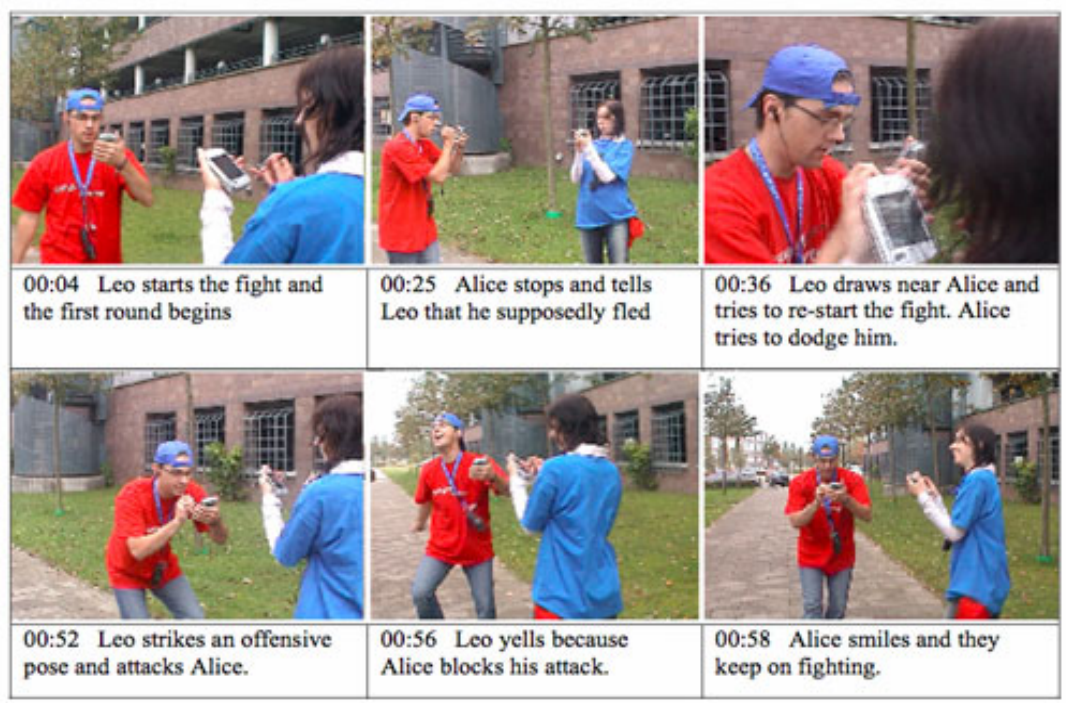

Fig. 3. The German fight

We prefer to describe the different behavior and hesitate to explain it. We tended to assign the behavioral difference to the different culture. Meanwhile having discussed the case study with further researchers from different cultural background, German and Chinese, we perceive the different behavior to reflect the culturally different border between the private and the public sphere: while the German players play the game within their native world, within which they do not hesitate to express their emotion directly, the Chinese players play within a foreign world, carefully hiding their emotion.

Table 1. The fights - structure and context dimension of the play activity

\begin{tabular}{|c|c|c|}
\hline & Fight Mechanics - game logic & Fight Mode - context \\
\hline Chinese & $\begin{array}{ll}\circ & \text { Enter the field physically } \\
\circ & \text { Identify the enemy physically }\end{array}$ & $\begin{array}{ll}\circ & \text { Chary } \\
\circ & \text { Kept physical distance } \\
\circ & \text { Focus: virtual level }\end{array}$ \\
\hline German & & $\begin{array}{ll}\circ & \text { Offensive, expressive } \\
\circ & \text { Pestered each other } \\
\circ & \text { Focus: virtual \& real level }\end{array}$ \\
\hline
\end{tabular}




\section{The Process-Oriented Method}

In the following we briefly introduce the process-oriented method and the way we applied it in our analyses of each play-test, before we particularly elaborate the methodical meaning of the difference between system and context for the processoriented method.

The goal of the process-oriented method is to study change within the process, within which it happens. We usually do this by means of an iterative cycle consisting of five analytically separable steps, cf. [10]

1. Understand the play process and the steps by which it is unfolding.

2. Identify game events, which either irritate you or change the course of the process.

3. Identify the state before and the state after the irritating or process-changing event.

4. Analyze both dimensions of the play process and the game event included: the goal oriented structure of the play process on the one side, and the varying context of play on the other side.

5. Understand the change in the process by means of the results gained in steps 3 and 4 .

In the case study we report here, we applied all five steps iteratively to understand each game play process sequentially.

\subsection{Data Collection and Analysis}

We aimed for collecting data, allowing us to access the process of the game play: process data streams. We looked for the minimum of these streams, required to understand the game at the level of the whole game, the level of the gang, and the level of the single player: server log-files of all game events, and client log-files of the step-by-step interaction, a re-playable visualization of all runner movements and game logical events during the game play on the map, video-recordings of four runners' play activities, video-recordings of the facial expressions of one boss, Automatic screen-capture of this boss' PC, audio-recordings of the internal gang communications.

Step 1: First, understand the game process as a whole at the level of the game and the level of the gang, watch the recordings several times, particularly the visualization of runners' movements throughout the game. Leadings questions are: who is the winner, how does the game unfold, what are the main phases; how is the game unfolding from the perspective of the different gangs; how does the win/loss ratio change for each gang over time. The outcome of this step is a sequence of meaningful main game phases, often visualized by a time line of events. Second, understand the game process as a whole at the level of a single player: watch the available observation videos of single players, and understand the player's communication with other players. The outcome is a temporal sequence of meaningful phases of the process for the single player.

Step 2: Identify single game events, which are irritating, surprising or differing from the expected or planned behavior from the perspective of the player or of the researcher. In the reported play-tests surprising were the fight events and the different behavior of the German and the Chinese players. 
Step 3: Analyze the process state before and the state after of the event. If the single event changes the course of the game you have to understand, what, why and how the change happens. What was the course of the game process and what was the player's intention before the change. What is the effect of the event on the further course? For example in the German play-test reported here: after the observed fight both German players concentrated on fighting against each other again and again, ignoring other play possibilities and own strategies outlined before the event. Another outcome at the research process level: After this case study we changed our idea of social interaction in mobile games. We assumed from the beginning a strong physical dimension of social interaction, what we assigned to empirical phenomena resembling the German fight mode [10]. The Chinese fight mode kind of irritated and surprised us. Their social interaction is characterized by a different physical quality like distance, caution, focus on the virtual level, we have not imagined designing the fight mechanics.

Step 4: Analyze both dimensions of the process, the event included: the goal oriented structure and the context of play. A possible outcome of the structural analysis is a temporal sequence of play actions, which follow the game logic, and in line with player intentions, which of course may also deviate from the game logic. The purpose of the contextual analysis is to understand the varying situations. An outcome is both, analytical categories, which evolve throughout the analysis, and empirical indices of behavioral differences, to describe the unexpected behavior, unexpected by the player or the researcher. As the main purpose of this paragraph on the process-oriented method is to understand the methodical meaning of this fourth element of the five steps we refer to the next section.

Step 5: Describe and try to develop an explanation of the observed behavior by using the results of step 3 and 4 , see for example chapter 2 in this paper.

\subsection{On the Methodical Meaning of System and Context}

In the current paragraph we particularly emphasize one element of the processoriented method, the step 4, which we applied to compare two fights from different play-tests. The goal of the comparison was to understand how the interplay of the game system and the context of play works. The goal now is to elaborate on its methodical meaning.

The process-oriented method we use to study play experiences and to evaluate mobile games takes into account that time matters: every time a game is played, it is played differently. As Salen and Zimmerman [11] state: "How does pleasure emerge and evolve over time in a game? All of the possible states and experiences of a game are contained within the theoretical construct called the space of possibility. A game player begins his or her journey through the space of possibility at the same place every time: the start of the game. But the experiential path that a player takes through the space will vary each time the game is played. Every play of the game will be unique, even though the rules of the game, its formal structure, remain fixed. This quality of games, that a game provides the same consistent structure each time but a different experience and outcome every time it is played, is a powerful engine that sustains and encourages play. We refer to this concept by the shorthand term same-but-different." P. 340. 
What is valid with regard to the sequential repetition of a game by one person, in that the person follows the logic of the same processing game system, however, in different ways, is valid in our case with regard to the parallel repetition of a game by different persons. They follow the logic of the same processing game system, however, in different ways.

The requirement of the fourth step of the process-oriented method in the case we presented here was to analyze the goal-oriented structure of the process here the fight mechanics sequentially applied by the opponents, and the changing context of play, here the very different fight modes.

The methodical meaning is first that we are able to analyze the game process by means of quantitative methods as far as it is organized by the game logic, second that we have to apply qualitative methods if we want to understand the context of play and third, that the concrete fight event allows to understand how both methods work together.

\section{On the Relevance of Studying Emergent Game Play}

Players have the power to change the logic of a game. Hardcore players often try to outsmart the system, see for example [12]. And even being a naive casual player you apply the game system to your particular context. Emergent game play is the first step of transforming a game logic. The identical fight mechanics in our case study worked with different cause-effect relations established within the emerging context of play. Repeated over time players develop implicit rituals and rules by means of which they adapt the game logic to their particular context of play. Families playing a card game do that all time. These implicit rules become explicit as soon as an outsider suddenly interrupts the flow and a conflict on how to interpret the rules has to be resolved by negotiation. Operative rules may result in a redefined game within which the old logic becomes a restructured part of a new system implemented either socially and/or technically.

\section{Summary and Conclusion}

We presented a comparison of two fights, which worked with the same fight mechanics and different play modes and made the difference between system and context of play discernable. We introduced the process-oriented method and elaborated on the methodical meaning of the difference between system and the context of play. We finally pointed to the relevance of studying game play process-oriented.

To study game play processes by means of the process-oriented method allows researchers to understand concretely the power of players inventing play possibilities and even changing a game. To play-test game prototypes and studying the process of play step by step allows the game designer to learn from players. Longitudinal studies of continuously running mobile game play processes will become an important instrument of future game design. 


\section{References}

1. Montola, M., Stenros, J., Waern, A.: Pervasive Games. Theory and Design. Morgan Kaufmann, San Francisco (2009)

2. Barnard, L., Yi, J.S., Jacko, J.A., Sears, A.: Capturing the effects of context on human performance in mobile computing systems. Personal and Ubiquitous Computing 11(2), 81-96 (2007)

3. Juul, J.: A Certain Level of Abstraction. In: Baba, A. (ed.) Situated Play: DiGRA 2007 Conference Proceedings, pp. 510-515. DiGRA, Tokyo (2007), http://www. jesperjuul. net/text/acertainlevel/

4. de sá, M., Carrico, L., Duarte, L., Reis, T.: A framework for mobile evaluation. In: Proc. ACM CHI 2008, April 5-10, pp. 2673-2678 (2008)

5. Crabtree, M., Benford, S., Greenhalgh, C., Tennent, P., Chalmers, M., Brown, B.: Supporting Ethnographic Studies of Ubiquitous Computing in the Wild. In: Proceedings of the ACM Conference on Designing Interactive Systems, DIS 2006, pp. 60-69 (2006)

6. Sherwood, S., Reeves, S., Maitland, J., Morrison, A., Chalmers, M.: Adapting Evaluation to Study Behaviour in Context. International Journal of Mobile Human Computer Interaction 1(2), 37-55 (2009)

7. Reid, J., Hull, R., Clayton, B., Melamed, T., Stenton, P.: A research methodology for evaluating location aware experiences. International Journal Personal and Ubiquitous Computing Theme Issue: Player Experiences in Location Aware Games - Methodological Issues (to be published in 2010)

8. Binder, D., Wang, L.: Chinese and German players playing on the Streets. Collaborative Master theses; Binder, D.: Cultural diversity and its impact on media design. Hochschule Bremen (2008); Wang. L.: Mobile Games: Interfaces and the cultural context of their use. Universität Bremen (2008)

9. Grüter, B.M., Breuer, H., Wollenberg, A.: Genese von Wissen in aufgabenorientierten Gruppen. Eine Fallstudie zur Wissensarbeit in der kommerziellen Softwareentwicklung. In: Witte, E.H. (Hrsg.) Leistungsverbesserungen in aufgabenorientierten Kleingruppen, pp. S149-S179. Pabst Science Publishers, Lengerich (2000)

10. Grüter, B., Oks, M.: On the Physical Dimension of Social Interaction in Mobile Games. In: Magerkurth, C., Åkesson, K.-P., Bernhaupt, R., Björk, S., Lindt, I., Ljungstrand, P., Waern, A. (eds.) PerGames 2007. Proceedings of the 4th International Symposium on Pervasive Gaming Applications, Salzburg, Austria, June 11-12 (2007), http: / /www. informatik.hs-bremen. de/gob/daten/ texte/grueter_oks.pdf

11. Salen, K., Zimmerman, E.: Rules of Play. In: Game Design Fundamentals, The MIT Press, Cambridge (2004)

12. Aarseth, E.: I Fought the Law: Transgressive Play and the Implied Player. In: Baba, A. (ed.) Situated Play. Proc. DiGRA 2007, September 24-28, pp. 130-133. The University of Tokyo, Tokyo (2007) 